\title{
SALIVA AS A DIAGNOSTIC MEDIUM
}

\author{
Richard Pink ${ }^{\mathrm{a}}$, Jiri Simek ${ }^{\mathrm{a}}$, Jana Vondrakova ${ }^{\mathrm{b}}$, Edgar Faber ${ }^{\mathrm{b}}$, Petr Michl ${ }^{\mathrm{a}}$, \\ Jindrich Pazdera ${ }^{\mathrm{a}}$, Karel Indrak ${ }^{\mathrm{b}}$
}

\author{
a Department of Oral and Maxillofacial Surgery, University Hospital, Olomouc, 775 20, Czech Republic; \\ ${ }^{b}$ Department of Hemato-Oncology, University Hospital, Olomouc, 77520 Czech Republic \\ e-mail: richard.pink@seznam.cz
}

Received: March 23, 2009; Accepted: May 7, 2009

Keywords: Saliva/Biomarkers/Diagnostics

Background: This is a review of current knowledge on the use of saliva, gingival cervical fluid and mucosal transudate in the detection of some oral and systemic diseases as well as drugs. Oral fluid is a diagnostic medium that can be easily collected and with minimal invasion but it has been neglected in the past. Today, saliva is being used more often to diagnose: HIV virus, oro-facial and systemic tumors, cardiovascular disease and in detecting addictive substances. Neutropil levels in saliva may also indicate successful bone marrow transplant. Oral fluid is now systematically being researched and oral fluid analysis is being compared with the analysis of other diagnostic media such as blood and urine .

A number of recent studies have focused on oncogenic marker detection and its monitoring in saliva. The latest clinical and laboratory findings on diagnostic markers of oropharyngeal carcinoma in oral fluid could be the beginning of their wider use as a diagnostic medium. Oral fluid can also be also used to diagnose other malignancies such as breast cancer which was one of the first malignant tumors to be detected using genetic protein biomarkers. Raised levels of CA15-3 and the epidermal growth factor (EGF) receptor have been found in patients with breast cancer and elevated levels of CA 125 and the glycoprotein complex in the saliva of ovarian cancer patients.

Conclusion: Doubtless, the diagnostic value of saliva, aided by current technological development will increase rapidly in the near future.

\section{INTRODUCTION}

The idea of using saliva in diagnostics was made in the second half of the 20th century. Its main advantage is easy and non invasive sample taking compared to peripheral blood. As with the latter, salivary analysis has two main objectives: early detection of certain diseases and monitoring the disease course in conjunction with treatment. A third use is in the detection of addictive drugs.

This is a review of current options for using saliva as a diagnostic medium in the case of certain illnesses and for drug detection.

\section{The physiology of saliva.}

Saliva is the secretion of the salivary glands which ensures stability in the oral cavity environment. "Oral fluid" is composed of saliva itself, gingival cervical fluids contained in the dentogingival sulcus, mucosal transudate, cell detritus, bacteria and food remains ${ }^{1}$. The basis of saliva is interstitial fluid from blood capillaries which enters via the salivary gland ducts where it is modified from isotonic into hypotonic fluid ${ }^{2}$. The salivary glands are innervated via the autonomic nervous system whereas the salivary center is the salivary nucleus in the medulla oblongata with the control center in the hypothalamus.

Saliva is composed $98 \%$ water. The remaining $2 \%$ is made up of other important compounds, such as electrolytes ( $\mathrm{Na}, \mathrm{K}, \mathrm{Ca}, \mathrm{Mg}$, hydrogen carbonates, and phos- phates), mucus composed mainly of mucopolysaccharides and glycoproteins, antiseptic substances (hydrogen peroxide, $\operatorname{Ig} \mathrm{A}$ ), and various enzymes ( $\alpha$-amylase, lysozymes, lingual lipase).

The average daily volume of saliva production is 500 $1000 \mathrm{ml}$. The submandibular gland produces $70 \%$ of the overall volume, the parotid gland $25 \%$, and the sublingual gland about $5 \%$. The minor salivary glands' share in the overall volume of saliva is insignificant.

Saliva has a whole range of functions: it participates in smooth digestion and the ingestion of food; mediates taste sensations; and cooperates in repairing soft tissue, maintaining the balance of oral microflora, ensuring the stability of the oral cavity environment, and remineralizing enamel. Most importantly, a whole range of immune and defensive processes take place via the salivary proteins.

A lack of saliva (xerostomia) not only has a negative impact on oral health but also on the health of the body as a whole. Xerostomia is most often induced through prescription medicines such as beta blockers, sedatives and antipsychotic medication. Autoimmune syndromes like Sjögren's syndrome which the authors discuss in this review, constitute the second large grouping. Insufficient saliva can result in the disruption of microbial balance to the benefit of certain pathogens such as Candida albicans and Streptococcus mutans.

Saliva produced by the sublingual, submandibular, and minor mucosal glands is very rich in mucins (MUC5B and MUC7) and contains only a small amount of amy- 
Table 1. The Functions and Composition of Saliva.

\begin{tabular}{|l|l|l|l|}
\hline \multirow{4}{*}{ teeth } & remineralization & PRP, Statherin, Ca Phosphate \\
\cline { 3 - 4 } & $\begin{array}{l}\text { inhibition } \\
\text { of demineralization }\end{array}$ & Mucins \\
\cline { 3 - 4 } & lubrication & PRP, Mucins \\
\cline { 3 - 4 } & buffering & Bicarbonate Phosphate Proteins \\
\cline { 3 - 4 } & \multirow{3}{*}{ food } & digestion & Lipase Amylase Protease \\
\cline { 3 - 4 } & taste & Zinc \\
\cline { 3 - 4 } & bolus & Mucins \\
\cline { 3 - 4 } & \multirow{3}{*}{ microbes } & antiviral & Mucins Ig Cystatins \\
\cline { 3 - 4 } & antifugal & Ig Mucins Histatins \\
\cline { 3 - 4 } & antibacterial & $\begin{array}{l}\text { Mucins Histatins Cystatins Lactoferrin Agglutinin Lysozym } \\
\text { Lactoperoxidas }\end{array}$ \\
\hline
\end{tabular}

Table 2. Salivary Biomarkers with Their Possibilities for Use.

\begin{tabular}{|l|l|}
\hline Saliva/Oral Fluid Biomarkers & Possibilities for Use \\
\hline DNA & $\begin{array}{l}\text { Standard genotyping } \\
\text { Bacterial infection } \\
\text { Diagnosing carcinomas of the head and neck } \\
\text { Forensics }\end{array}$ \\
\hline RNA & $\begin{array}{l}\text { Viral/bacterial identification } \\
\text { Carcinomas of the head and neck }\end{array}$ \\
\hline Proteins & $\begin{array}{l}\text { Diagnosing periodontitis } \\
\text { Diagnosing carcinomas of the head and neck } \\
\text { Detecting dental cavities }\end{array}$ \\
\hline Mucins/glycoproteins & $\begin{array}{l}\text { Diagnosing carcinomas of the head and neck } \\
\text { Detecting dental cavities }\end{array}$ \\
\hline Immunoglobulins & Diagnosing viruses (HIV, hepatitis B and C) \\
\hline Metabolites & Diagnosing periodontitis \\
\hline Drugs and their metabolites & $\begin{array}{l}\text { Monitoring drug abuse } \\
\text { Detecting of drugs in the body }\end{array}$ \\
\hline Viruses, bacteria & Epstein-Barr virus reactivation (mononucleosis) \\
\hline Cellular material & Diagnosing carcinomas of the head and neck \\
\hline
\end{tabular}

lase. In contrast, saliva from the parotid gland is rich in amylase (20\%), proline-rich proteins (60\%), and phosphoproteins - statherin ( $7 \%$ ), but without representation of mucins.

Statherins (from the Greek statheropio meaning "to stabilize"), as protease inhibitors, have a main role in maintaining balance during the creation and eventual degradation of enamel and its minerals.

Proline-rich proteins have a similar structure to statherin and also have the same defensive function. These are the main components of the enamel pellicle which, as a $0.1 \mu \mathrm{m}$ thick layer, protects against the disturbance of tooth enamel by bacteria and inhibits demineralization. Serum proteins, salivary proteins, and glucans are also components of this layer, in addition to proline-rich proteins.

The main function of the MUC5B mucin is to protect hard and soft tissues by creating a molecular gel layer against microbacterial, chemical, and physical influence. This layer lowers tooth abrasion and protects teeth against other mechanical damage. Substitution of this protein is often possible using carboxymethyl cellulose, mucins from animal saliva, and xanthan (a polysaccharide with high molecular weight resulting from the fermentation of saccharides by the Xanthomonas campestris bacterium). MUC5B only binds to a limited number of oral bacteria, such as Helicobacter pylori, Haemophilus parainfluenzae, Candida albicans, and, not least, to the HIV-1 virus. 


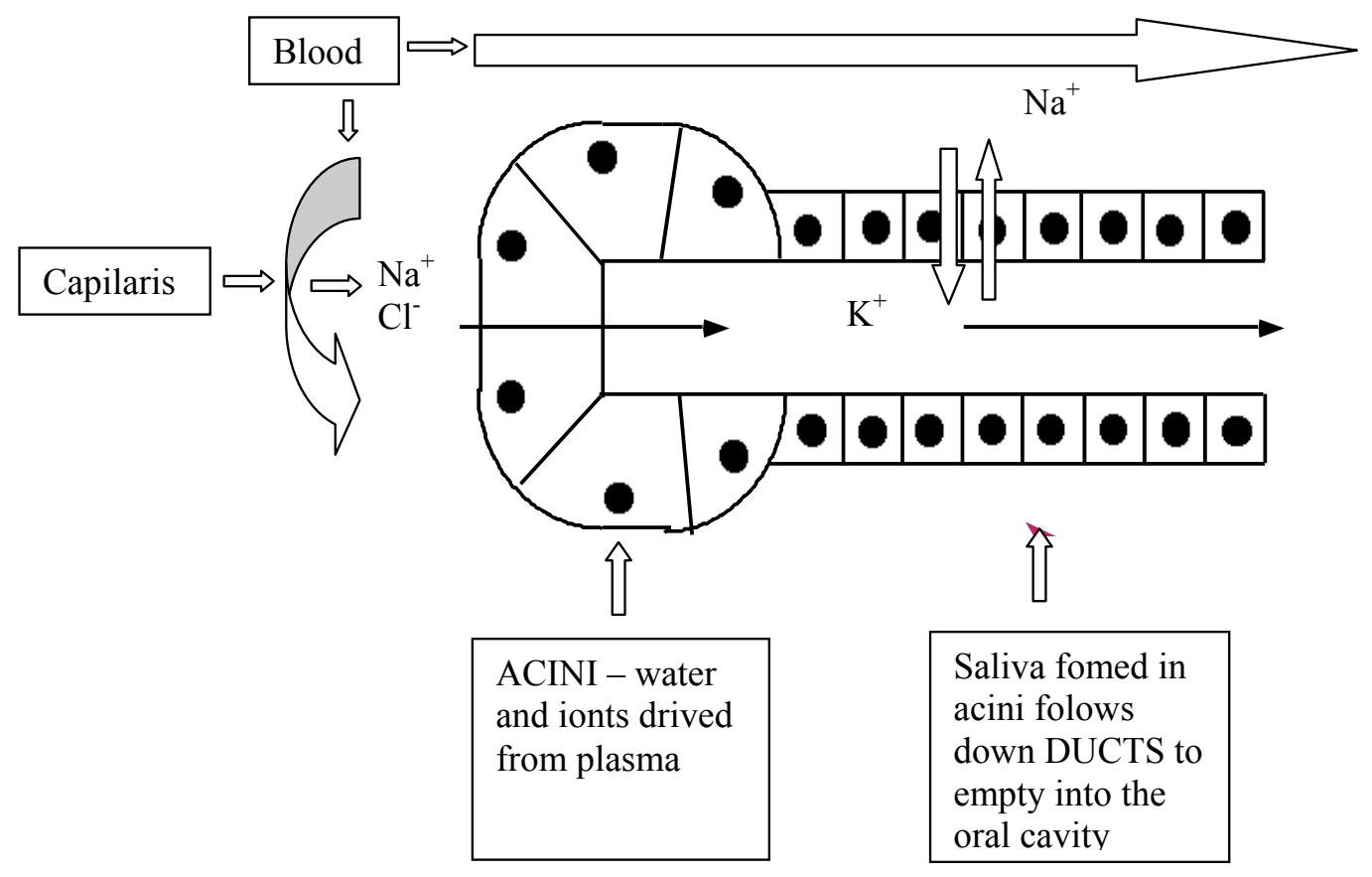

Fig. 1. The Ion Transport Mechanism from Serum to the Salivary Canal.

Owing to its low molecular weight, the MUC7 mucin easily binds to bacteria and viruses (HIV) and thus ensures oral bacterial clearance. On the other hand, as the main component of pellicules, it supports the adhesion of bacteria - mainly Streptococcus mutans - to the tooth surface and thus supports their colonization in the oral cavity. Without mucins in the saliva, mucous loses its mechanical resistance and the result is greater susceptibility to various inflammatory and infectious complications. One of a number of antibacterial substances in saliva is $\operatorname{Ig} \mathrm{A}$ which binds bacteria by agglutination. IgA originates in the lymphatic cells of mucous, the tonsils, and Peyer's patches, collectively called mucosa-associated lymphoid tissue.

Lactoferrin also plays an important role; by binding iron ions, an integral part of the bacteria's nourishment, it disables their use by bacteria. Conversely, sialoperoxidase is an enzyme that catalyzes the reaction of bacteria's metabolic product - hydrogen peroxide with salivary thiocyanate - during the formation of oxygen radicals which are toxic to bacteria.

Saliva also contains many other proteins such as histatin and polypeptides with antibacterial and antifungal properties contained only in saliva. Lysozyme is an enzyme in saliva, tears, nasal mucosa, blood plasma, lymphocytes, and mother's milk. Owing to its ability to disrupt the bacterial wall, it has strong antibacterial properties. The function of cystatins, inhibitors of bacterial cysteine-proteases, and lysed leukocytes which can play a significant role in periodontal disease are not entirely clear. It is also important to mention salivary alpha-amylase, a digestive enzyme for breaking down starch into sugars and which is created in the salivary glands.

\section{Saliva in diagnosing autoimmune diseases}

Autoimmune diseases make up a diverse group of disorders with an estimated prevalence of 5-8 \% (USA). These are generally failures of the autoimmune system leading to organ damage in the afflicted individual. One problem in relation to these malfunctions is that they are difficult to diagnose and their underlying etiology is uncertain.

One of the most common autoimmune diseases is Sjögren's syndrome which mainly afflicts women in their 4th-5th decades. It is a chronic disease affecting the lachrymal, salivary, and other exocrine glands; viruses of the HTLV-1 type play a significant role in its pathogenesis. The result is decreased secretions of these glands. A new classification differentiates two forms of Sjögren's syndrome, primary and secondary ${ }^{3}$. Primary Sjögren syndrome afflicts the lachrymal and salivary glands but not the connective tissue unlike the secondary type connected to rheumatoid arthritis, SLE, polyomyositis, primary biliary cirrhosis, thyreoiditis and/or vasculitis. In addition to diseases of the eye (keratoconjunctivitis) and joints (polyarthritis), we encounter oral symptoms which consist of insufficient salivation, making swallowing and pronunciation difficult. Hyposialia also has a negative effect as increasing dental cavities. Most distinctively, hyposialia develops on the tongue's mucous membrane where it results in atrophy of the papillae. The oral mucosa of the oral cavity is dry and a reddish color. The overall picture of those afflicted is dominated by enlarged parotid glands, a subfebrile state, raised levels of erythrocyte sediment, and anemia and lymphocytosis in the blood count. Given the higher prevalence of malignant B-MALT (mucosa-associated lymphoid tissue) lymphoma, Sjögren's syndrome is considered to be precancerous ${ }^{4,5}$. 
The classification criteria for diagnosing Sjögren's syndrome was established in the years 1989-1996 by the European Study Group on Classification Criteria for Sjögren's Syndrome (ESGCS) ${ }^{6}$. Today, the diagnostics of Sjögren's syndrome is based on clinical symptomatology and histopathological examination supplemented by sialometry for measuring the production of salivary secretions. An exploratory excision is performed under local anesthesia, most often on the mucous membrane of the lower lip. The histopathological picture shows an visible inflammatory infiltrate with the presence of T and B lymphocytes, overall atrophy of the acinar cells, and dilation of the tubules with overall fibrosis of the tissue?

Owing to diverse symptomology and insufficiently sensitive and specific laboratory markers, the diagnosis of Sjögren's syndrome is problematic.

In the past, there was an attempt to use serum markers (serum cytokines - IL-6, TNF-alpha, BAFF, lysosome enzymes, and a range of antibodies) in diagnosing Sjögren's syndrome. However, none of these demonstrated sufficient specificity. Similar biomarkers were monitored in saliva, but, as with blood, they were not sufficiently conclusive or specific.

Recently, modern methods of protein analysis have begun to be utilized in diagnosing Sjögren's syndrome. Ryu et al. ${ }^{8}$ analysed salivary proteins with the help of protein chips - /surface-enhanced laser desorption/ionization time-of-flight mass spectrometry/ (SELDI-TOF-MS). They demonstrated a raised level of lactoferrin, beta 2 microglobulin, lysozyme $\mathrm{C}$, cystatin $\mathrm{C}$, and a decrease in salivary amylase and carbonic anhydrase in the case of Sjögren's syndrome. To confirm the reliability of this method however further studies are necessary. Genetic analysis of peripheral blood has revealed differences in the metabolism of Interferon I in Sjögren's syndrome, systemic lupus erythematosus, dermatomyositis and psoriasis.

\section{Using saliva in oncological diagnostics \\ Malignant tumors of the oral cavity}

Worldwide, oropharyngeal cancers are among the 10 most frequent malignancies with an annual 500,000 new cases being reported. In spite of improved and more aggressive therapy however, only 30-40\% of such patients survive for longer than 5 yrs This can be ascribed to late diagnosis, poor tumour response to chemo- and radiotherapy, as well as insufficient biomarkers for diagnostics and post-therapeutic tumor monitoring. Biopsy followed up by histopathological examination is still the mainstay for reliable diagnosis of orofacial tumors. One way of increasing the range of diagnostic options in the case of primary oral tumors and recurrence is to monitor the level of selected biomarkers which have adequate sensitivity and specificity.

Oral fluid is a diagnostic medium which is collected easily and it is minimally invasive. Much has also been published on the detection of DNA biomarkers to diagnose spinocellular carcinoma of the oral cavity. A mutation of the tumor suppressor gene p53 is common to many malignancies. For malignant tumors of the head and neck, the mutation can be up to $50 \%$. This is confirmed in a number of studies that analyze mutation of the p53 oncogene by the PCR Method ${ }^{9}$. Using the ELISA method, the p53 antibody was detected in $13 \%$ of patients $(3 / 23)$ treated for spinocellular carcinoma of the oral cavity ${ }^{10}$. To date however, none of the DNA markers has yet found a firm place in diagnosing spinocellular carcinoma of the oral cavity.

Other research has been directed to detecting the human papillomavirus (HPV 16 DNA) in saliva, as one of many etiologic agents. The incidence of HPV positivity in patients treated for cancer of the oral cavity is estimated to be more than $45 \%$ (ref. ${ }^{11}$ ). However, in only $57 \%$ of those with the disease, was it possible to detect the HPV16 subtype from mouthwash with a sensitivity level of $32.6 \%$. Another study also points to the low sensitivity and specificity and this limits the use of this Metod ${ }^{12}$.

A more recent trend is the detection of protein markers in the diagnosis of spinocellular carcinoma of the oral cavity. For example, the level of carcinoembryonic antigen (CEA) in saliva in the presence of malignancies of the oral cavity is increased, while the level of gastrointestinal cancer antigen is decreased ${ }^{13}$. The level of human alphadefensin-1 (HNP-1), as a protein marker, is reduced in patients after the surgical removal of tumour. This protein marker was not detected in healthy people ${ }^{14}$.

More than 309 salivary proteins commonly occurring in healthy individuals have been identified by the University of Los Angeles laboratoriem ${ }^{15}$. Of these, IL8 and thioredoxin are utilized in the diagnostics of spinalcellular carcinoma. Wong et al. ${ }^{16}$ demonstrated raised levels of IL8 and mRNA in spinocellular carcinoma of the oral cavity that are many times higher than for simple inflammation (periodontitis) which according to the authors ensures sufficient marker specificity.

Oral fluid is also used in diagnosing other malignancies. Breast cancer was one of the first malignant tumors to be detected with the help of genetic protein biomarkers. Streckfus et al. ${ }^{17}$ drew attention to raised levels of CA15-3 and of the epidermal growth factor (EGF) receptor in patients with breast cancor while Di-Xia, Schwartz, and Fan-Qin ${ }^{18}$ described elevated levels of CA 125 and the glycoprotein complex in the saliva of patients with ovarian cancer.

\section{Hematological oncology}

In recent years, publications have appeared on the detection of neutrophils in the oral fluids of hematological oncology patients after bone marrow transplants. Wright et al. ${ }^{19}$ sought to establish a level of neutrophils in oral fluid that potentially indicated the success of bone marrow transplants. They detected neutrophils in the saliva 2-3 days earlier than in the peripheral blood. In healthy people, they found duirnal fluctuating levels of neutrophils in the saliva. Gorgun et al. ${ }^{20}$ confirmed Wright's conclusions and also reported that the level of neutrophils in saliva drops during myeloablative treatment to zero one day later than in the blood and conversely rises (1-2 days) earlier than the level of neutrophils in the blood. Cheretakise et al. ${ }^{21}$ determined the level of neutrophils 
indicating the graft's incorporation after a bone marrow transplant as $0.25 \times 104 / \mathrm{ml}$. In a group of 29 patients, they found a rise in level of neutrophils in saliva earlier than that in the peripheral blood. They also examined the importance of oral mucositis after myeloablative chemotherapy and found improvement was related to the appearance of neutrophils in the saliva again. This indirectly drew attention to the significance of neutrophils in the healing of salivary lesions. These authors consider the presence of neutrophils in saliva to be evidence of "saturating" tissue with neutrophils and on that basis they hypothesised that the time interval for bone marrow graft's incorporation is directly proportional to the saturation of the tissue with neutrophils and that the individual in question will have a lower susceptibility to infectious complications ${ }^{21}$. Lieschke et al. point to a steep rise in neutrophils after administering growth factors (G-CSF) in both blood and saliva which again proves their interdependence ${ }^{22}$.

\section{Saliva in diagnosing cardiovascular disease}

It is possible to detect salivary alpha-amylase as a protein biomarker using chromatography or immunoanalysis. Alpha-amylase plays a unique role among biomarkers as an enzyme composed of 13 glycosylated hydrolases.

In contrast to many compounds present in oral fluid, salivary alpha-amylase is not actively transported to the oral fluid. Nor does it diffuse passively from the blood. This enzyme is created directly in the salivary glands. The level of salivary alpha-amylase does not correlate with the level of systemic amylase in the blood or in the digestive system. Salivary alpha-amylase is not represented in the saliva from birth and its presence is linked to the infant's intake of solid food. The absence of salivary alpha-amylase in infants up until roughly 7 months of age ensures the intake of antibodies from mother's milk, on which amylases, as macromolecules with immunogenetic potential, could have a destructive influence.

The main function of salivary alpha-amylase, similar to pancreatic amylase, is to break down sugars. Salivary alpha-amylase also has antibacterial properties with positive impact on oral health. There is a proven inverse relation between activity of salivary alpha-amylase and number of dental cavities, periodontal disease and level of bacteria in the saliva.

The latest studies also report raised activity of salivary alpha-amylase connected to stress in adolescents who had levels measured at $145 \%$ higher than the average ${ }^{23}$.

Other studies have confirmed increase in this enzyme in the presence of cardiovascular disease. Chatterton et al. ${ }^{24}$ corroborated the direct relationship between raised levels of alpha-amylase and heart rate which increases under stress. Further, a positive relation between activity of the sympathetic nervous system and level of alphaamylase has been found ${ }^{25}$. Also very important is the correlation between rise in alpha-amylase and reduction of the pre-ejection period as this is a very good gauge of sympathetic nervous system activity.

\section{The significance of saliva for diagnostic testing of medicines and drugs.}

Diagnostic testing of drugs and prescription medicines using saliva/oral fluid is now widespread and replacing the previously used urine.

The salivary glands, which create saliva as the main component of oral fluid, are highly vascular and this facilitates the easy crossing over of drugs and medicines from blood to saliva. Within a number of minutes of parenteral transmission, a substance can be detected in the oral fluid. Certain drugs such as amphetamines and cocaine appear in saliva before they do in plasma owing to their acidity. Generally it can be said that the level of drugs, medicines, or their metabolites remain in saliva from a number of hours up to days after their intake.

\section{Amphetamine}

Amphetamine is a sympathomimetic amine with centrally stimulating activity. Amphetamine and its metabolites are excreted in the urine. However, the amount of excreted amphetamine depends on the urine's $\mathrm{pH}$. If the $\mathrm{pH}$ is acidic, about $60 \%$ is excreted; however if the $\mathrm{pH}$ becomes alkaline the amount of excreted amphetamine rapidly drops to $1-5 \%\left(\right.$ ref. $\left.{ }^{26}\right)$.

Amphetamine is also produced in the organism as a product of metabolizing methamphetamine. It appears in the oral fluid soon after reaching a given concentration in the plasma. Wan et al. ${ }^{27}$ conducted a study in which they changed the $\mathrm{pH}$ of saliva by administering soda or ammonium chloride. Even when the saliva's $\mathrm{pH}$ was relatively constant, the level of amphetamine metabolites was distinctly lower after ammonium chloride.

\section{Barbiturates}

Barbiturates are pharmaceuticals with sedative and hypnotic effect used for treating convulsive states in addition to inducing anesthesia. We can divide barbiturates into short-acting - (e.g. amobarbital) - and long-acting (e.g. phenobarbital). They are addictive substances amd commonly used orally. Clinical studies examining the presence of barbiturates in oral fluids are relatively few given their addictive nature. The highest concentration of amobarbital was determined in oral fluid 1 hour after oral administration, during which a constant level persisted for 50 hours $^{28}$.

\section{Benzodiazepines}

This is a large group of pharmaceuticals with hypnotic, sedative, antipsychotic, and antiepileptic effect. Generally, they are lipophilic molecules with low solubility in water and rapid absorption from the GIT. For monitoring levels in oral fluid, diazepam is the benzodiazepine of choice owing to its frequent use. However, as with barbiturates, studies on this subject are relatively limited. It has been shown that the level of diazepam, or rather its metabolite nordiazepam, appears in oral fluids after about 45 minutes $^{29}$. 


\section{Cannabis, Marijuana}

This is a psychoactive substance naturally occurring in the plant Cannabis sativa. It is used around the world as a so-called soft drug. Most often, marijuana enters the body via smoking. Therefore, its levels in oral fluids are relatively high, which is ascribed to the smoking rather than active transport by saliva ${ }^{30}$. In recent studies, it has been shown that it is possible to detect marijuana from oral fluid roughly 30 minutes after passive inhalation. However, a more recent study has overturned this theory using more precise measurements ${ }^{32}$.

\section{Cocaine}

Cocaine is a local anesthetic and vasoconstrictor present in large amounts in the coca plant. The main effect of cocaine is short-term stimulation followed by euphoria necessitating a repeated doses. In oral fluid, we find cocaine after all forms of administration, however mainly after smoking and intranasal administration. The levels in saliva last roughly one hour after intake but they quickly decrease soon after and are then similar to levels in the blood ${ }^{33}$.

\section{Nicotine}

Nicotine is an alkaloid primarily contained in tobacco products. It is metabolized in the organism into cotinine and 3-hydroxycotinine. These two metabolites are used primarily when monitoring their levels in oral fluid for determining the intensity of passive smoking ${ }^{34}$. For example, this method is used in pregnant women.

\section{Heroin}

Heroin is an acetylated derivative of morphine, prepared from opium and administered most often intravenously. Its high lipophilicity enables rapid distribution in the central nervous system with a resulting euphoria ${ }^{35}$.

Its level in oral fluid is comparable to the values in plasma, with maximum levels after probably 2 minutes. When smoked, its levels in oral fluid are higher; however, after 30-60 minutes, they decrease to the values in peripheral blood ${ }^{36}$.

\section{Morphine}

As with other opioids, morphine acts through the opioid receptors in the brain resulting in analgesia, mood change, and the onset of dependence after long-term administration. It is possible to detect morphine in oral fluids very soon after parenteral administration. In Cone's study, a mere 45 minute delay after intramuscular administration was described in comparison to plasma ${ }^{37-39}$.

Although morphine is a rapidly metabolized by conjugation, only free morphine has been detected in saliva. It is also possible to determine morphine in saliva after intravenous administration, smoking heroin, or eating poppy seeds ${ }^{40,41}$.

\section{Codeine}

Codeine is a medicine for suppressing pain and coughing which is metabolized by oxidation into morphine ${ }^{35}$. Most often, it is administered orally, often in combina- tion with other pharmaceuticals. A dosage of $60-120 \mathrm{mg}$ of codeine is detected in oral fluid after 1 hour with a maximum concentration after 1.6-1.7 hours ${ }^{42}$. The concentration of codeine in oral fluids is 3-4 times greater than in plasma ${ }^{42}$.

\section{Infectious disease}

The last twenty years has seen no major global increase in the infectious diseases apart from AIDs. This is the result of extensive research and the development of new vaccines, medicines, and antibiotics. If the resources used in the Western world spread to developing countries, there is the presumption that the number of infectious diseases will decline even more. The main goal of research now is to focus on multiresistant bacteria such as MRSA as well as on viral infections such as HIV and HPV.

\section{Bacterial infection}

There are over 500 bacteria present in the oral cavity, most of which are nonpathogenic and are in symbiosis with other bacteria. Using various molecular methods and types of cultivation, the isolation of periodontal and cariogenic bacteria has been accomplished using various oral cavity samples. Routinely used methods do not enable detection of primary pathogenic bacteria which cause diseases of the lungs and upper and lower respiratory tracts. For example, a positive test for Mycobacterium tuberculosis was detected in oral fluid by the PCR method at $98 \%$, but using regular cultivation, it was only $17.3 \%$ (ref. ${ }^{43}$ ). Only when this infectious disease is in an acute state and the level of bacteria is very high, do Mycobacteria appear in the oral cavity in a greater number.

Helicobacter pylori is considered to be the most common cause of peptic ulcers and is also currently a risk factor for carcinoma and mucosa-associated lymphoid tissue lymphoma. The bacteria is transmitted via the fecal-oral route, but there exists very little work aimed at cultivating this bacteria from oral or fecal samples ${ }^{44}$. The golden standard of cultivation is thus still biopsy of stomach mucous membrane and subsequent cultivation. Detection of specific Helicobacter pylori DNA with the help of the PCR method in saliva samples in symptomatic patients enables detection of infection in its active state ${ }^{43}$.

Methods of detecting Mycobacterium tuberculosis and Helicobacter pylori show that although healthy bacteria are not directly detectable in the oral fluid, saliva contains markers of these pathogens. In addition to DNA, other markers such as 16S RNA sequences have also been described $^{45}$. In diagnosing streptococcal pneumonia, the detection of pneumococcal C-polysaccharides is used in saliva without the detection of nucleic acids.

\section{Viral infection}

Detection of the human immunodeficiency virus (HIV) is a very good example of using saliva to diagnose infectious disease. The number of infected patients is continually increasing. Creating antibodies directly for the viral protein epitopes together with the development of techniques abling detection of these proteins has made testing for HIV infection easier ${ }^{46}$. For example, when de- 
tecting HIV using the ELISA method in combination with the Western blot test, saliva is, compared to blood and urine has greater advantage owing to its higher specificity and sensitivity ${ }^{47}$. Saliva can also be used to measure the levels of beta- 2 microglobulins and/or the levels of tumor necrosis factor-alpha receptors and confer the possibility of monitoring the activity of the HIV virus or AIDSrelated inflammatory disease ${ }^{47}$.

Conversely, some studies have described a level of HIV virus in saliva that is 2-3 times lower than in the blood $^{49}$. Therefore, the results are still unclear and often controversial $^{50}$. Given that no vaccine has been developed against HIV infection to date, detection of antiviral antibodies remains standard for identifying infected people and determining the risk of transmitting the infection. Current studies are therefore focused primarily on detecting antibodies and the $\mathrm{p} 24$ gene $^{51}$.

Direct detection and identification of the presence of the virus in saliva using the PCR method is gradually becoming the standard method. Detecting the RNA of viruses such as dengue fever, hepatitis C, or the HIV virus is however more complicated because single-stranded RNA is much less stable than double-stranded DNA. The sample collection technique and correct procedure are key to valid results. The best solution is to use PCR to diagnose infection with the HPV 8 virus. Detection of this virus in saliva or nasal fluids is used as proof of the non-sexual transmission of this virus. ${ }^{52}$ PCR is also used for diagnosing CMV and HPV 6, 7, and 8 in saliva with patients with $\mathrm{HIV}^{53}$.

A newer PCR method is used to diagnose lymphotropic viruses such as the EB virus, CMV, and HPV 6, 7, and 8.52 This method is also used to diagnose human forms of rabies $^{54}$.

Lastly the detection of salivary EB virus antigens using RIA (radioimmunoassay) is used in epidemiological studies in school children ${ }^{55}$.

\section{CONCLUSION}

As a diagnostic medium, oral fluid had been neglected until recently. Today is it being used more often in diagnosing the HIV virus, orofacial and systemic tumors, cardiovascular disease, and in detecting addictive substances. Oral fluid is now being systematically researched and the results of its analysis are being compared with other diagnostic media such as blood and urine. The latest clinical and laboratory findings on diagnostic markers of oropharyngeal carcinoma in oral fluid could be the beginning of their wider use as diagnostic media, with the primary advantages being easy sample collection, minimal invasiveness and financial accessibility.

\section{REFERENCES}

1. de Almeida Pdel V, Grégio AM, Machado MA, de Lima AA, Azevedo LR. Saliva composition and functions: a comprehensive review. J Contemp Dent pract. 2008; 9:72-80.
2. Turner RJ. Mechanisms of fluid secretion by salivary glands. Ann. NY Acad. Sci 1993; 694:24-35.

3. Kassan SS, Moutsopoulos HM.Clinical manifestation and early diagnosis of Sjögren's syndrome. Arch. Intern. Med. 2004; 164: 1275-84.

4. Kassan SS, Thomas TL, Moutsopoulos HM, et al. Increased risk of lymphoma in sicca syndrome. Arch. Intern. med. 1978; 89: 888-92

5. Theander E, Henriksson G, Ljungberg O, Mandl T, Manthorpe $\mathrm{R}$, Jacobsson LT. Lymphoma and other malignancies in primary Sjögren's syndrome: a cohort study on cancer incidence and lymphoma predictors. Ann. Rheum. Dis 2006; 65:796-803.

6. Vitali C, Bombardieri S, Jonsson R. The European Study Group on classification criteria for Sjögren's syndrome: a revised version of the American-European Consensus Group. Ann. Rheum. Dis 2002; 61: 554-8.

7. Daniels TE. Labial salivary gland biopsy in Sjögren's syndrome: assessment as a diagnostic tool criterion in 362 suspected cases. Arthritis Rheum 1984; 27: 147-56.

8. Ryu OH, Atkinson JC, Hoehn GT, Illei GG, Hart TC Identification of parotid salivary biomarkers in Sjögren's syndrome by surface-enhanced laser desorption ionization-time-of-flight-mass spectrometry and two-dimensional difference gel electrophoresis. Rheumatology (Oxford) 2006; 45: 1077-86.

9. Boyle JO, Mao L, Brennan JA, et al. Gene mutations in saliva as molecular markers for head and neck squamous cell carcinomas. Am J Surg 1994; 168: 429-32.

10. Warnakulasuriya S, Soussi T, Maher R, Johnson N, Tavassoli M Expression of $\mathrm{p} 53$ in oral squamous cell carcinoma is associated with the presence of $\operatorname{IgG}$ and IgA p53 autoantibodies in sera and saliva of the patients. J Pathol 2002; 192: 52-7.

11. Zhao M, Rosenbaum E, Carvalho AL, et al. Feasibility of quantitative PCR-based saliva rince screening of HPV for head and neck cancer. Int J Cancer 2005; 117: 605-10.

12. Smith EM, Ritchie JM, Summersgill KF, et al. Human papillomavirus in oral exfoliated cells and ris of head and neck cancer 2004; 96: 449-55.

13. Negri L, Pacchioni D, Calabrese F, Giacomasso S, MastromatteoV, Fazio M. Serum and salivary CEA and GICA levels in oral cavity tumors. Int J Biol Markers 1988; 3: 107-12.

14. Mizukawa N, Sugiyama K, Fukunaga J, et al. Defensin-1, a peptide detected in the saliva of oral squamous cell carcinoma pacients. Anticancer Res 1998; 18: 4645-9.

15. Hu S, Xie Y, Ramachandran P. Large- scale identification of proteins in human salivary proteome by liquid chromatography/mass spectrometry two-dimensional gel electrophoresis-mass spectrometry. Proteomics 20055 (6) 1714-1728.

16. St John M, Li Y, Zhou X et al. IL - 6 and IL8 potential biomarkers for oral cavity and oropharyngeal SCCA. Arch. Otolaryngol. Head Neck surg. 2004; 130: 929-935.

17. Streckfus CF, Bigler L, Dellinger TD, Dai X, Kingman A, Thigpen JT. The presence of c-erbB-2, and CA 15-3 in saliva and serum among women with breast carcinoma: a preliminary study. Clin Cancer Res 2000; 6: 2363-2370.

18. Di-Xia C, Schwartz P, Fan-Qin L Salivary and serum CA 125 assays for detecting malignant ovarian tumors. Obstet Gynecol 1990; 75: 701-704.

19. Wright DG, Meierovics AI, Foxley JM. Assessing the delivery of neutrophils to tissues in neutropenia. Blood 1986; 67: 1023-1030.

20. Gorgun A, Knight DR, Wright GD. Use of oral mucosal neutrophil counts to detect the onset and resolution of profound neutropenia following high-dose myelosuppressive chemotherapy. American Journal of Hematology 2003; 72: 13-19.

21. Cheretakise C, Dror Y, Glogauer M. A non invasive oral rinse assay to monitor engraftment, neutrophil tissue delivery and susceptibility to infection following $\mathrm{HSCI}$ in pediatric patients. Bone Marrow Transplantation 2005; 36: 227-232.

22. Lieschke GJ, Ramenghi U, O'Connor MP, Sheridan W, Szer J, Morstyn G. Studies of oral neutrophils levels in patients receiving G-CSF after autologous marrow transplantation. British Journal of Haematology 1992; 82: 589-595. 
23. Gordis EB et. al. Asymmetry between salivary cortisol and alphaamylase reactivity to stress: relation to aggresive behavior in adolescents. Psychoneu-roendocrinology 2006; 31: 976-987.

24. Chatterton RT et. al. Salivary alpha-amylase as a measure of endogenous adrenergic activity 1996; 16: 433-448.

25. Bosch JA et. al. Innate secretory immunity in response to laboratory stressors that evoke distinct patterns of cardiac autonomic activity. Psychosom. Med. 2003; 65: 245-58.

26. Beckett AH, Rowland M. Urinary excretion kinetics of amphetamine in man. J.Pharm. Pharmacol., 1965; 17: 628-638.

27. Wan SH, Matin SB, Azarnoff DL. Kinetics, salivary excretion of amphetamine isomers, and effect of urinary $\mathrm{pH}$. Clin.Pharmacol. Ther. 1978; 23: 585-590.

28. Inaba T, Kalow W. Salivary excretion of amobarbital in man. Clin Pharmacol.Ther. 1975; 18: 558-562.

29. Di-Gregorio GJ, Piraino AJ, Ruch E. Diazepam concetrations in parotid saliva, mixed saliva and plasma. Clin.Pharmacol.Ther 1978; 24: 720-725.

30. Huestis MA, Cone EJ. Relationship of delta-9-tetrahydrocannabinol in oral fluid to plasma after controlled administration of smoked cannabis.J.Anal.Toxicol.2004; 28: 394-399.

31. Niedbala RS, Kardos KW, Salamone S. et al. Passive cannabis smoke exposure and oral fluid testing, J.Anal.Toxicol., 2004; 28 : 546-552.

32. Niedbala RS, Kardos KW, Fritch EF et al. Passive cannabis smoke exposure and oral fluid testing. II. Two studies of extreme cannabis smoke exposure in a motor vehicle J.Anal.Toxicol. 2005; 29: 607 615.

33. Cone EJ, Oyler J, Darwin WD. Cocaine disposition in saliva following intravenous, intranasal, and smoked administration. J. Anal. Toxicol. 1997; 21: 465-475.

34. Ëtzel RA. A review OF the use OF saliva conitine as a marker OF tobacco smoke exposure Prev.Med.1990; 19: 190-197.

35. Rook EJ, Van Ree JM, Van Den BW et al. Pharmacokinetics and pharmacodynamics of high doses of pharmaceutically prepared heroin, by intravenous or by inhalation route in opioid-dependent patients. Basic.Clin.Pharmacol. Toxicol. 2006; 98: 86-96.

36. Jenkins AJ, Oyler JM, Cone EJ. Comparison of heroin and cocaine concetrations in saliva with concentrations in blood and plasma. J.Anal.Toxicol. 1995; 19: 359-374.

37. Cone EJ, Dickerson S, Paul BD, Mitchell JM, Forensic drug testing for opiates V.Urine testing for heroin, morphine, and codeine, with commercial opiate immunoassays. J.Anal.Toxicol. 1993; 17: 156-164.

38. Cone EJ. Saliva testing for drug abuse. Ann.N.Y.Acad.Sci. 1993; 694: 91-127.

39. Jenkins AJ, Oyler JM, Cone EJ. Comparison of heroin and cocain concentrations in saliva with concentration in blood and plasma J.Anal.Toxicol, 1995; 19: 359-374.

40. Rohrig TP, Moore $\mathrm{C}$. The determination of morphine in urine and oral fluid following ingestion of poppy seeds J.Anal.Toxikol. 2003; 27: 449-452.
41. Kim I, Barnes AJ, Oyler JM et al. Plasma and oral fluid pharmacokinetics and pharmacodynamics after oral codeine administration Clin.Chem. 2000; 48: 1486-1496.

42. Eguchi J, Isihara K, Watanabe A, Fukumoto Y, Okuda K. PCR method is essential for detecting Mycobacterium tuberculosis in oral cavity samples. Oral.Microbiol.Immunol. 2003; 18(3): 156-159.

43. Shames B, Krajden S, Fuksa M, Babida C, Penner JL. Evidence for the occurence of the same strain of Campylobacter pylori in the stomach and dental plaque. J.Clin.Microbiol., 1989; 27(12): 2849-2850.

44. Tiwari SK, Khan AA, Ahmed KS et al. Rapid diagnosis of Helicobacter pylori infection in dyspeptic patients using salivary secretion: a non-invasive approach. Singapore Med.J. 2005; 46(5): 224-228.

45. Granstrom G, Askelof P, Granstrom M. Specific immunoglobulin A to Bordetella pertussis antigens in mucosal secretion for rapid diagnosis of whooping cough. J.Clin.Microbiol., 1988; 26(5): 869874 .

46. Scully C. HIV topic update: salivary testing for antibodies, Oral. Dis.,1997; 3: 212-215.

47. Martinez PM, Torres AR, Ortiz de Lejarazu R, Montoya A, Martin JF, Eiros JM. HIV antibody testing by enzyme-linked fluorescent and western blot assays using serum, gingival -crevicular transudate, and urine samples. J.Clin.Microbiol. 1999; 37: 1100-1106.

48. Grant RM, Piwowar EM, Katongole-Mbidde E et al. Comparison of saliva and serum for human immunodeficiency virus type 1 antibody testing in Uganda using a rapid recombinant assay. Clin. Diag.Laboratory Immunol. 1996; 3: 640-644.

49. Luizzi G, Chirianni A, Clementi M, Zaccarelli M, Antinori A, Piazza M. Reduction of HIV-1 viral load in saliva by indinavir -containing antiretroviral regimen. 2002; 16(3): 503-504.

50. Baron S, Poast J, Cloyd MW. Why is HIV rarely transmitted by oral secretions? Saliva can disrupt orally shed, infected leukocytes. Arch.Intern.Med., 1999; 159 (3): 303-310.

51. Ly TD, Ebel A, Faucher V, Fihman V, Laperche S. Could the new HIV combined p24 antigen and antibody assays replace p24 antigen specific assays? J.Virol. Methods 2007; 143(1): 86-94.

52. Blackbourn DJ, Lennette ET, Ambroziak J, Mourich DV, Levy JA. Human herpesvirus 8 detection in nasal secretion and saliva J.Infect. Dis. 1998; 177: 213-216.

53. LaDuca JR, Love JL, Abott LZ, Dube S, Freidman-Kien AE, Poiesz BJ, Detestion OF human herpes virus 8 DNA sequences in tissues and bodily fluids. J.Infect. Dis. 1998; 178: 1610-1615.

54. Crepin P, Audry L, Rotivel Y, Gacoin A, Caroff C, Bourhy H Intravitam diagnosis of human rabies by PCR using saliva and cerebrospinal fluid. J.Clin.Microbiol. 1998; 36: 1117-1121.

55. Crowcroft NS, Vyse A, Brown DW, Strachan DP. Epidemiology of Eppstein-Barr virus infection in pre-adolescent children: application of a new salivary method in Edinburgh, Scotland. J.Epidemiol. Community Health, 1998; 52: 101-104. 